MAURICIO VICO SÁNCHEZ

DEPARTAMENTO DE DISEÑO

FACULTAD DE ARQUITECTURA Y URBANISMO

UNIVERSIDAD DE CHILE

SANTIAGO, CHILE

MVICO@UCHILEFAU.CL

JUAN CARLOS ORTIZ

POSGRADO EN DISEÑO INDUSTRIAL,

FACULTAD DE ARQUITECTURA,

UNIVERSIDAD NACIONAL AUTÓNOMA DE MÉXICO,

CIUDAD DE MÉXICO, MÉXICO.

JCORTIZNICOLAS@POSGRADO.UNAM.MX

ERIKA CORTÉS

POSGRADO EN DISEÑO INDUSTRIAL,

FACULTAD DE ARQUITECTURA,

UNIVERSIDAD NACIONAL AUTÓNOMA DE MÉXICO, CIUDAD DE MÉXICO, MÉXICO.

PDI_7@POSGRADO.UNAM.MX

Cómo citar: Vico, M., Ortíz, J. \& Cortés, E. (2021)

Editorial: Diseño y transformación social:

reflexiones, análisis y direcciones futuras

RChD: creación y pensamiento, 6(10), 01-04.

https//doi.org/10.5354/0719-837X.2021.63947

Revista Chilena de Diseño,

RChD: creación y pensamiento

Universidad de Chile

2021, 6(10)

http://rchd.uchile.cl

\section{Diseño y transformación social: reflexiones, análisis y direcciones futuras}

\author{
Design and Social Transformation: Reflections, Analysis \\ and Future Directions
}

El Diseño como disciplina que ejerce su praxis en la sociedad actual, requiere un corpus de saberes y de actitudes acordes con las nuevas estructuras sociales, culturales, económicas y políticas. Nos traslada ahora a un conjunto de conocimientos de carácter multidisciplinarios y nos obliga a su transformación social.

Esta edición y las anteriores nos llevan a reflexionar y a asumir nuestro rol como universidades comprometidas con la generación de nuevos conocimientos, con su objetivo mayor en las reverberancias de estos temas en la comunidad local e internacional, y una bajada concreta en el desarrollo continuo de una publicación de carácter científico. Así justifican su existencia la Universidad de Chile en particular, y nuestra revista RChD en el Departamento de Diseño, para hacer realidad su dimensión y su impacto en la ciudadanía. Dan a conocer una multitud de contenidos a través de artículos que responden a investigaciones que vienen desde el campo académico. Esta es su más sentida razón de ser, con la cual la política de la revista ha estado comprometida desde su fundación.

Por otra parte, es la preocupación del Comité Editorial de la revista $\mathrm{RChD}$, y una de sus políticas, abrir nuevas tramas que se desarrollan en el área cada vez más amplia del Diseño y buscar afanosamente la posibilidad de conectar la diversidad de campos del conocimiento. Esto es especialmente relevante en nuestra disciplina, que abarca una variedad y complejidad de contenidos, entre ellos el Diseño y la transformación social y que ha puesto en reflexión la globalización y sus consecuencias.

Ya instalado en una comunidad de investigadoras/es, el tema del Diseño y su impacto social en tiempos de crisis, sus dimensiones e implicancias éticas (como el enfoque sistémico y sus impactos culturales, medioambientales y políticos) deben repercutir en cambios sociales profundos.

Este nuevo número de la revista de Diseño RChD: Creación y pensamiento, volumen 6, número 10, está dedicado al "Diseño y transformación social" porque consideramos que es una de las dimensiones del Diseño más relevantes: la creación de artefactos, objetos, o interfaces que se insertan en la vida cotidiana, cuya su dimensión socializadora que no se limita a factores humanos, más bien considera la vida en la Tierra. Esta edición nos invita a realizar una reflexión y mirada crítica a la dimensión social, no solo desde la disciplina del Diseño también en otras, como la sociología, la antropología o la filosofía. Así, en esta serie de artículos se aborda la transformación social desde diferentes dimensiones, agrupadas en cuatro temas: agencia y Diseño, afectividad, saberes locales y, Diseño para la transición y complejidad. Los autores respondieron al llamado y a la pregunta que se hacían los editores invitados: ¿por qué generar un nuevo artefacto que se insertará en una realidad particular? En varios de los artículos se busca responder: "si bien 
el Diseño transforma una realidad, también es transformado por ella, pues existe una interacción sistémica compleja".

Es en esa dimensión social, más allá de su concepción clásica, y revisarlo como un fenómeno holístico y paradigmático en sus esferas de producción industrial, objetual, de enseñanza y otros. La disciplina del Diseño se ve enriquecida a medida que entra en contacto con otras disciplinas, se abre a otras experiencias, a otras miradas y, se expande más allá del oficio del hacer.

En la variedad de tópicos que desarrollan los artículos de este número, subyace la enseñanza de que estamos insertos en un mundo cada vez más social y que entra lentamente a un período de transformaciones. El sujeto no solo se rodea de objetualidades; éstas tienen fuertes repercusiones sociales, culturales y antropológicas que nos obligarán a mirar nuestra pertenencia y el tipo de sociedad que queremos construir.

Para la Universidad Nacional Autónoma de México, entidad a la que están adscritos los editores invitados, un tema fundamental de discusión es el impacto social, en un sentido muy amplio, que tiene la práctica del Diseño. Por ello nos hemos dado la tarea de abordar el tema en diferentes escenarios, por ejemplo, a partir de los cursos que impartimos, las conferencias en las que participamos y concretamente, en el desarrollo de este tipo de publicaciones donde se presentan, analizan, comentan, contrastan y complementan perspectivas relacionadas al impacto del Diseño para realizar una transformación social. En este sentido consideramos que se ha cumplido el objetivo del llamado que estructura a este número de la revista. La selección fue compleja y minuciosa y se presentan los artículos que cumplieron cabalmente con todos los criterios de RChD.

El artículo "Especialista en Diseño ¿sujeto, actor o agencia/agente? en retos sociales" reflexiona sobre tres roles involucrados en la práctica del diseñador/a al abordar un reto de Diseño. El texto profundiza en cómo cada rol determina las decisiones y los impactos de la propuesta de Diseño, y cuestiona el supuesto tradicional de que el diseñador/a puede generar cambios significativos en la sociedad tan solo por ejercer la disciplina.

"El Diseño pone la mesa" desarrolla el tema del poder transformacional del Diseño, potenciado a través del emprendimiento social. Sugiere que, a partir de esta orientación, la disciplina conquista una posición desde la cual puede definir con mayor agencia el área de oportunidad o el sistema a transformar.

El artículo "La dimensión afectiva: una propuesta política de Diseño para la emancipación" desarrolla una aportación filosófica que enriquece el planteamiento teórico de Arturo Escobar. Propone un punto, el afectivo, para derivar en futuros nuevos caminos para la creación de mundos posibles y posibilitantes desde el Diseño.

En "TiUD 2020: la emergencia de la amistad durante el distanciamiento social" se presenta una reflexión sobre el desarrollo de relaciones significativas y experiencias profundas de aprendizaje-enseñanza. Esto surge a partir de la transición de la educación hacia la digitalización, resultado de la 
emergencia por el virus Covid-19, específicamente en relación con el trabajo realizado en el Taller Interuniversitario de Diseño (TiUD).

"Prótesis bioclimáticas: interface emancipadora para la libre adaptabilidad de los espacios transicionales" versa sobre las capacidades del Diseño para ser agente en la transformación social y cómo las personas pueden influir en la creación de prótesis bioclimáticas, al reconocer la importancia de la naturaleza material y los conocimientos técnicos propios de las comunidades para fomentar la autoconstrucción y el mantenimiento.

El artículo "Moda y apropiación cultural: reflexiones críticas desde la identidad y el Diseño" aborda el concepto de apropiación cultural para los procesos creativos del Diseño, que, en la práctica, estimula la invisibilización del otro. Un resultado es el impedimento de la creación de un vínculo social entre diseñadores, marcas y comunidades usufructuadas, donde se niega, en último término, la alteridad necesaria para la construcción identitaria de ambos grupos humanos.

En "Diseño para las transiciones: enseñanza desde las identidades y los saberes artesanales", se propone una ruta teórico-práctica, que conlleve a la elucidación de un Diseño situado en las identidades y los procesos productivos locales. Se basa en las articulaciones posibles que emergen al poner en diálogo el saber del Diseño y los múltiples saberes artesanales existentes en el contexto colombiano.

"Diseño y sistemas complejos: un enfoque multidimensional en el proceso de Diseño" brinda un marco conceptual que permite replantear y generar nuevas formas de pensamiento hacia mejores prácticas.

La diversidad de planteamientos alrededor de la temática de este número es, también, una exploración de las posibilidades del Diseño como disciplina. Esta característica, es una invitación a que diseñadores/as aborden retos desde nuevas direcciones, por ejemplo, experienciales al explorar planteamientos para concebir otras reconfiguraciones del sistema en que vivimos, en donde conceptos como transformación, transición y transmutación son centrales para este tipo de discusiones. Es fundamental en estos momentos generar escenarios para establecer condiciones en las cuales las y los diseñadores se enfrenten a la transformación, complejidad y ambigüedad, para reconocer y considerar en su práctica las circunstancias de los tiempos que vivimos. Además, los escenarios apoyan al entendimiento de la interconexión de lo social, económico, político y los sistemas naturales, posibilitando dar dirección a retos de Diseño en todos los niveles de la escala espacio-temporal, con fines diversos, como mejorar la calidad de vida, impactar en los bienestares, o relacionarse de mejor manera con el medio ambiente.

Es importante para los editores invitados dar las gracias a todas las personas que acompañaron el desarrollo de este número, al editor general y la coeditora por aceptar el tema de este número, y a los/las autores/as que enviaron sus propuestas a la revista, pues son artífices de las discusiones que emergen de sus artículos. También agradecemos al equipo de evaluadores de América 
Latina y Europa, que con sus comentarios y observaciones fortalecieron el trabajo realizado en esta región. Este es un tema que queremos resaltar porque la comunidad de diseñadores-investigadores se está consolidando (o quizá ya está consolidada). Es lo que observamos en el cuerpo que existe en nuestra región: revistas especializadas, editores, investigadores y revisores. $Y$ es algo digno de celebrar. Esperamos que este número contribuya en esa dirección. Diseño que se expande más allá del oficio del hacer.

Finalmente, bajo la variedad de tópicos que desarrollan los artículos de este nuevo número subyace la enseñanza de que la tierra no pertenece a las personas, sino las personas pertenecen a la tierra. 